\title{
ChemComm
}

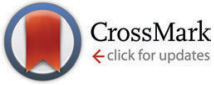

Cite this: Chem. Commun., 2015, 51, 15386

Received 22nd July 2015, Accepted 25th August 2015

DOI: $10.1039 / \mathrm{c} 5 \mathrm{cc} 06128 \mathrm{~h}$

www.rsc.org/chemcomm

\section{A $\pi$-electron deficient diaminotriazine functionalized MOF for selective sorption of benzene over cyclohexane $\dagger$}

\author{
Biplab Manna, $\ddagger^{\mathrm{a}}$ Soumya Mukherjee, $\ddagger^{\mathrm{a}}$ Aamod V. Desai, ${ }^{a}$ Shivani Sharma, ${ }^{a}$ \\ Rajamani Krishna ${ }^{\mathrm{b}}$ and Sujit K. Ghosh*a
}

\begin{abstract}
A diaminotriazine functionalized novel MOF (DAT-MOF-1) has been synthesized stemming out of a $\pi$-electron-deficient pore-surface functionalization based linker-design principle, which results in efficient selectivity of benzene sorption over its aliphatic analogue cyclohexane, crucial from the industrial standpoint.
\end{abstract}

Metal-organic frameworks (MOFs), formed by the coordination chemistry-assisted self-assembly process of organic linkers and metal ions, have evolved as one of the most preferred newgeneration materials, owing to their superlative potential in multifarious fields, such as gas storage, chemical separation, sensing, drug delivery, and catalysis. ${ }^{1}$ These crystalline materials score over the other classes of functional materials because of a few unique advantages, such as their unique periodical structures with long-range order, excellent porosity, framework flexibility, and tunable pore surface functionalization, which endow them with promising storage and separation applications. ${ }^{2}$ Among the diverse porous adsorbent materials utilized for serving efficient separation of flue gas and hydrocarbons, MOFs have established themselves as a uniquely promising class of functional adsorbents owing to the unmatched unison of their aforementioned characteristics. ${ }^{3}$

From the application perspective, the separation of liquid phase hydrocarbons, especially those having similar physical properties and comparable molecular sizes, is highly challenging for industrial applications. In this context, the industrially crucial separation of benzene (Bz) and cyclohexane (Cy) poses a challenge. The recognized difficulty behind this $\mathrm{C}_{6}$ hydrocarbon stream separation originates as a consequence of the

\footnotetext{
${ }^{a}$ Indian Institute of Science Education and Research (IISER), Dr. Homi Bhabha Road, Pashan, Pune, 411008, India. E-mail: sghosh@iiserpune.ac.in; Fax: +91202589 8022; Tel: +91202590 8076

${ }^{b}$ Van't Hoff Institute for Molecular Sciences, University of Amsterdam, Science Park 904, 1098 XH Amsterdam, The Netherlands

$\dagger$ Electronic supplementary information (ESI) available. CCDC 1414256. For ESI and crystallographic data in CIF or other electronic format see DOI: 10.1039/ c5cc06128h

\# B.M. and S.M. have contributed equally.
}

unavoidable production of cyclohexane during the catalytic hydrogenation of benzene in the benzene/cyclohexane miscible system and also due to their considerably close boiling points (benzene, $353.25 \mathrm{~K}$; cyclohexane, $353.85 \mathrm{~K}$ : Table S1, ESI $\dagger$ ), similar molecular volumes, comparable Lennard-Jones collision diameters along with low relative volatilities. ${ }^{4}$ While close proximity in their boiling points (difference: $0.6 \mathrm{~K}$ ) rules out conventional fractional distillation methods, specialized distillation protocols such as azeotropic and extractive distillation methods employed with entrainer species such as sulpholane, dimethylsulfoxide, $N$-methylpyrrolidone, and $N$-formylmorpholine involve high energy-intensive requirements. On the contrary, adsorptive separation offers an energy-efficient alternative to extractive distillation, especially for $\mathrm{Bz} / \mathrm{Cy}$ mixtures containing small percentages of benzene, as is commonly encountered.

Interesting enough, these two analogue species have distinct spatial configurational orientations; benzene is a planar $\pi$-cloud entity, while aliphatic cyclohexane exists in either chair or boat configuration (Fig. S1, ESI $\dagger$ ). This inherent dissimilarity might seem to be the imperative key factor behind efficiently separating the duo (Scheme 1). The favourable role of $\pi$-complexation with benzene behind the selective sorption-mediated $\mathrm{Bz} / \mathrm{Cy}$ separation was explored in cation-exchange Faujasite-type zeolites Na-Y, Pd-Y, Ag-Y, and FAU-type zeolite membranes; ${ }^{5}$ while

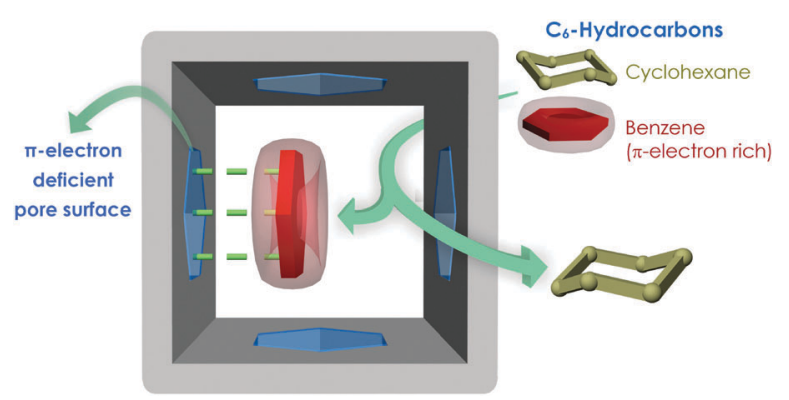

Scheme 1 Schematic representation of the strategic employment of $\pi$-electron deficient diaminotriazine (DAT)-functionalized pore surface for exhibiting a selective interplay with benzene over cyclohexane. 


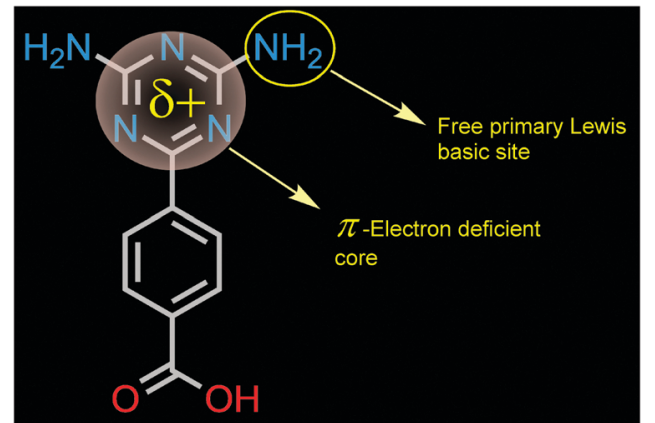

Fig. 1 Structure of the $\pi-\mathrm{e}^{-}$deficient triazine (DAT) core based linker (LH), with Lewis basic primary amino groups, imparting framework functionalization.

recent years have witnessed some porous MOF materials being used for the targeted selective sorption based separation of $\mathrm{Bz} / \mathrm{Cy}{ }^{4 b, c, 6}$ However, the ligand design-strategy derived achievement of such separation performance is indeed scarce. ${ }^{4 b, 6 g}$

Ligand functionalization based attainment of excellent separation performance by MOFs has witnessed remarkable upsurge in recent times, markedly motivated by the pioneering work of Chen et al. ${ }^{7}$ Over the years, the triazine core has been quite well-harnessed chiefly by Zhou et al., as constituent linkers in the MOF domain for presenting excellent adsorption features with concomitant thermal robustness of the materials. ${ }^{8}$ Under this backdrop, we intended to achieve Bz/Cy separation by the favourable $\pi-\pi$ stacking driven interplay of the $\pi$-electron deficient triazine core of the employed rigid carboxylate linker (Fig. 1) functionalized MOF pore surface and $\pi$-rich guest species benzene. ${ }^{9}$ Herein, for the first time, the electron deficient diaminotriazine (DAT) core of a new-fangled rigid monocarboxylic acid linker has been proficiently exploited for imparting essential $\pi$-electron deficiency to the ensuing new MOF (DAT-MOF-1) for achieving the targeted selective sorptionbased separation of benzene over cyclohexane at ambient temperature $(298 \mathrm{~K})$ and pressure $(1 \mathrm{~atm})$. The electrostatic surface potential (ESP) plot (Fig. S2, ESI $\dagger$ ) for the conceived linker was verified to have significant $\pi$-electron deficiency, which makes its choice strategically triggered. Upon reaction of ligand ( $\mathrm{LH}$ ) (Fig. S3, $\mathrm{ESI} \dagger$ ) and $\mathrm{Cu}\left(\mathrm{NO}_{3}\right)_{2} \cdot 3 \mathrm{H}_{2} \mathrm{O}$ under solvothermal conditions in the binary solvent system DMF/MeOH $(1: 1)$, block shaped green shiny single crystals of compound DAT-MOF-1a $\left[\left\{\mathrm{Cu}(\mathrm{L})_{2}\right\} \cdot x \mathrm{G}\right]_{n}$ (G refers to disordered guest molecules) are obtained (Fig. S7, ESI $\dagger$ ). A single-crystal X-ray diffraction (SC-XRD) study of the compound showed the formation of a two-dimensional (2D) network, which upon further hydrogen bond formation with similar 2D networks in proximity gave rise to intermolecular hydrogen bonded three-dimensional (3D) supramolecular networks (DAT-MOF-1a) (Fig. 2), crystallized in the orthorhombic space group Pbnb. The Adsym subroutine of PLATON was applied to confirm that no additional symmetry could be applied to the model. The asymmetric unit contains one $\mathrm{Cu}(\mathrm{II})$ center and two monocarboxylate DAT (deprotonated form of LH) linkers. Nearly five guest DMF molecules detected by the combined inputs of elemental analysis (ESI $\dagger$ ), IR spectral investigation and thermogravimetric analysis (Fig. S8 and S17, ESI $\dagger$ ) could not be located
A)

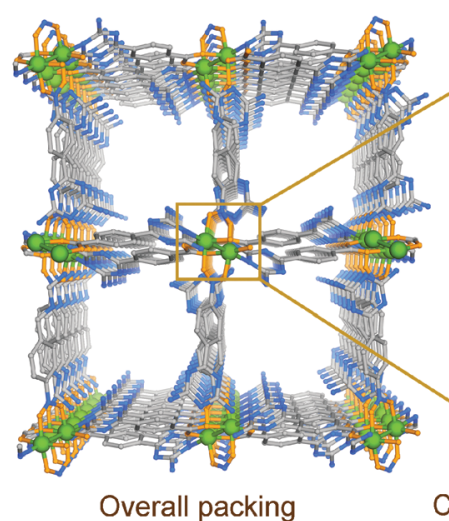

B)

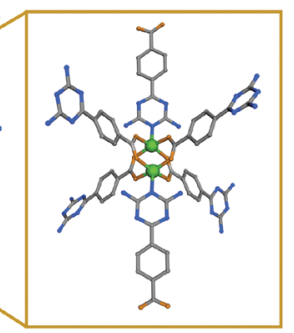

Fig. 2 (a) Perspective view of the overall packing of DAT-MOF-1a (guest molecules and $\mathrm{H}$ atoms are omitted for clarity); (b) Lewis basic $\mathrm{N}$-rich $\pi$-electron deficient coordination environment constructing DAT-MOF-1a, rendering channel functionalization.

in the asymmetric unit from Fourier maps in the refinement cycles, because of a high extent of disorder for these moieties in the crystal. The phase purity for the as-synthesized phase was confirmed by the PXRD analyses (Fig. S18, ESI $\dagger$ ) coupled with the SC-XRD-based unit cell analysis of arbitrarily chosen crystals from the bulk phase.

As observed from the perspective view of the supramolecular H-bonded 3D-framework, the pores along the $a$-axis (Fig. S11-S14, ESI $\dagger$ ) of dimensions $\sim 6.71 \times 7.08 \AA^{2}$ are well-decorated with Lewis basic pyridyl and primary amine functionalities, which should ideally facilitate strong interactions with polar guest species $\mathrm{CO}_{2}$ owing to the latter's high quadruple moment $\left(-13.4 \times 10^{-40} \mathrm{C} \mathrm{m}^{2}\right)^{10}$ over its congener flue gases. ${ }^{1 a, 11}$ The anticipated $\mathrm{CO}_{2}$-selective adsorption feature was indeed verified for the activated form of DAT-MOF-1a, namely DAT-MOF-1, as evident from the single component gas adsorption isotherms recorded at low temperatures ( $77 \mathrm{~K}$ and $195 \mathrm{~K}$ ). Exclusively for $\mathrm{CO}_{2}$, there was a distinct two step-mediated adsorption uptake observed with noteworthy hysteresis (typical signature of dynamic frameworks) (Fig. S20, ESI $\dagger$ ), owing to the concomitant host-guest interaction-driven dynamic structural transformations or breathing phenomena, accompanying the $\mathrm{CO}_{2}$ vapour sorption process. ${ }^{12}$ A prominent two-step sorption profile and the observed hysteretic desorption can be attributed to structural transitions between relatively open and closed framework structures as $\mathrm{CO}_{2}$ adsorptive gets adsorbed with substantial hysteresis consequential from the metastability of the more open structure, similar to the previous reports on breathing phenomena exhibited by soft porous crystalline frameworks. ${ }^{12 a, 13}$ On the flipside, no such steps were observed for the $\mathrm{CO}_{2}$ sorption isotherm at $298 \mathrm{~K}$ over a similar pressure range (Fig. S21, ESI $\dagger$ ), validating the dependency factor of the structural transitions accompanying the sorption process on the low temperature-mediated specific interactions of the host framework with guest $\mathrm{CO}_{2}$ molecules. The guest-free nature and excellent crystalline features of the activated phase DAT-MOF-1 were once confirmed from the thermogravimetric analyses (TGA) and Powder X-ray Diffraction (PXRD) profiles respectively 


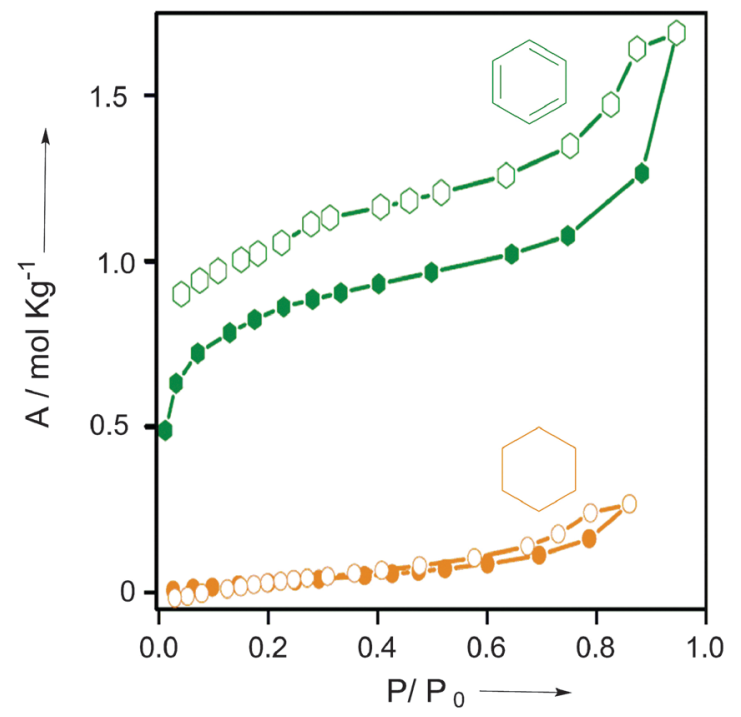

Fig. 3 Solvent sorption isotherms of compound DAT-MOF-1 recorded at $298 \mathrm{~K}$ for Bz and Cy. Closed and open symbols denote adsorption and desorption, respectively.

(Fig. S17 and S18, ESI $\dagger$ ), and the same was harnessed for the targeted selective vapor sorption based separation studies of benzene/cyclohexane.

Substantiating the anticipated selective interplay of $\mathrm{Bz}$ with DAT-MOF-1, the single component vapor sorption experiments for both the solvents $\mathrm{Bz}$ and $\mathrm{Cy}$ when measured at $298 \mathrm{~K}$, the striking difference between their respective uptake amounts (1.5 mol kg $\mathrm{kg}^{-1}$ for $\mathrm{Bz}$, while only $\sim 0.2 \mathrm{~mol} \mathrm{~kg}^{-1}$ for CY) was revealed (Fig. 3 and Fig. S22, ESI $\dagger$ ). ${ }^{13} \mathrm{C}$ NMR studies performed using the $\mathrm{DCl} / \mathrm{DMSO}-d_{6}$ digested samples after vapor exposure to the $\mathrm{Bz}$ and $\mathrm{Cy}$ solvent vapors and their $1: 1$ equimolar mixtures indubitably revealed exclusive Bz-selectivity (Fig. S23, ESI $\dagger$ ).

We evaluate Bz/Cy separation by utilizing the Ideal Adsorbed Solution Theory (IAST) calculations. Fig. 4a shows the experimental data for pure component isotherms of $\mathrm{Bz}$ and $\mathrm{Cy}$ in DAT-MOF-1; the continuous solid lines are Langmuir-Freundlich fits (the fit parameters being specified in Table S2, ESI $\dagger$ ). For fitting purposes, the sorption branches of the isotherms were solely considered. Fig. 4b shows IAST calculations of $\mathrm{Bz}$ uptake capacity for equimolar Bz/Cy mixtures in DAT-MOF-1. Notably, for pressures exceeding about $1 \mathrm{kPa}$, the adsorbed phase contains predominantly Bz. Fig. 4c presents IAST calculations for adsorption selectivity, $S_{\text {ads }}$, for equimolar Bz/Cy mixtures with values in excess of about 200, suggesting the viability of the present MOF material for vapor phase selective sorption based Bz/Cy separation at $298 \mathrm{~K}$. Transient breakthrough simulations, using the established methodology described in earlier work, ${ }^{14}$ confirm that sharp separations are obtained in a fixed bed adsorber; see Fig. 4d. The video animation-illustration (accompanied as ESI $\dagger$ ) evidently demonstrates that DAT-MOF-1 has both significantly higher selectivity and uptake for Bz over Cy.

In a nutshell, as a first-of-its kind convergent approach, the triazine core's $\pi$-electron-deficiency coupled with the mutual attendance of amino moieties for the reported DAT-MOF-1 has a)
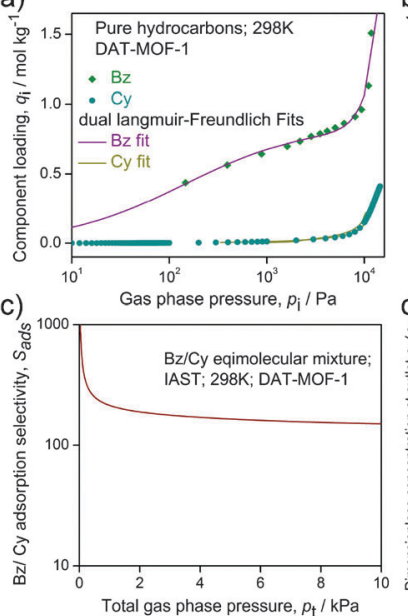

b)
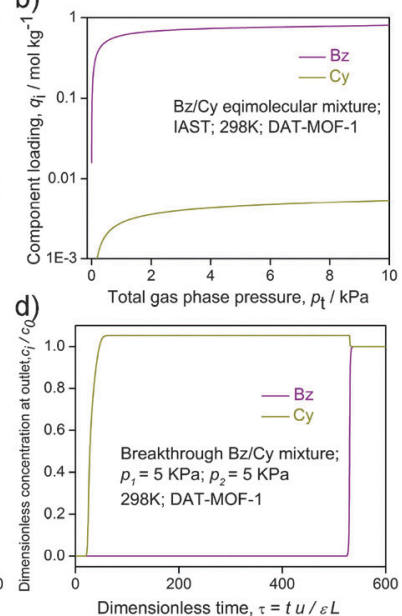

Fig. 4 (a) Comparison of experimental data for pure component isotherms for $\mathrm{Bz}$ and $\mathrm{Cy}$ in DAT-MOF-1 with dual-Langmuir-Freundlich fits that are shown by the continuous solid lines; (b) IAST calculations for Bz uptake capacity for equimolar Bz/Cy mixtures in DAT-MOF-1; (c) IAST calculations of adsorption selectivity for equimolar mixtures of $\mathrm{Bz} / \mathrm{Cy}$ in DAT-MOF-1; (d) breakthrough simulations for Bz/Cy in a fixed bed of DAT-MOF-1 at $298 \mathrm{~K}$.

been strategically exploited for the achievement of selective benzene sorption over its aliphatic analogue cyclohexane. Further investigations to consolidate its practical applications in terms of realistic industrial separation scenario are currently underway. This might indeed help to develop functional porous materials by virtue of their tunable functionalities; immensely important for exhibiting industrially crucial hydrocarbon separation features.

B.M. is thankful to CSIR for research fellowship, while IISER Pune is acknowledged for the same from S.M., A.V.D. and S.S.; DST (Project No. GAP/DST/CHE-12-0083) and DST-FIST (SR/FST/ CSII-023/2012) are acknowledged for generous financial support.

\section{Notes and references}

1 (a) Z. Zhang, Y. Zhao, Q. Gong, Z. Li and J. Li, Chem. Commun., 2013, 49, 653; (b) Z. Zhang, Z.-Z. Yao, S. Xiang and B. Chen, Energy Environ. Sci., 2014, 7, 2868; (c) J.-R. Li, Y. Ma, M. C. McCarthy, J. Sculley, J. Yu, H.-K. Jeong, P. B. Balbuena and H.-C. Zhou, Coord. Chem. Rev., 2011, 255, 1791; (d) J.-R. Li, J. Sculley and H.-C. Zhou, Chem. Rev., 2012, 112, 869; (e) Z. Hu, B. J. Deibert and J. Li, Chem. Soc. Rev., 2014, 43, 5815; $(f)$ S. S. Nagarkar, B. Joarder, A. K. Chaudhari, S. Mukherjee and S. K. Ghosh, Angew. Chem., Int. Ed., 2013, 52, 2881; (g) R. C. Huxford, J. Della Rocca and W. Lin, Curr. Opin. Chem. Biol., 2010, 14, 262; (h) P. Horcajada, R. Gref, T. Baati, P. K. Allan, G. Maurin, P. Couvreur, G. Férey, R. E. Morris and C. Serre, Chem. Rev., 2012, 112, 1232; ( $i$ ) J. Lee, O. K. Farha, J. Roberts, K. A. Scheidt, S. T. Nguyen and J. T. Hupp, Chem. Soc. Rev., 2009, 38, 1450; $(j)$ J. Gascon, A. Corma, F. Kapteijn and F. X. Llabrés i Xamena, ACS Catal., 2014, 4, 361 .

2 (a) M. P. Suh, H. J. Park, T. K. Prasad and D.-W. Lim, Chem. Rev., 2012, 112, 782; (b) J. L. C. Rowsell and O. M. Yaghi, Microporous Mesoporous Mater., 2004, 73, 3; (c) M. J. Rosseinsky, Nat. Mater., 2010, 9, 609; (d) S. Mukherjee, B. Joarder, A. V. Desai, B. Manna, R. Krishna and S. K. Ghosh, Inorg. Chem., 2015, 54, 4403; (e) S. Mukherjee, B. Joarder, B. Manna, A. V. Desai, A. K. Chaudhari and S. K. Ghosh, Sci. Rep., 2014, 4, 5761.

3 (a) Z. Kang, M. Xue, L. Fan, L. Huang, L. Guo, G. Wei, B. Chen and S. Qiu, Energy Environ. Sci., 2014, 7, 4053; (b) B. Li, H.-M. Wen, 
H. Wang, H. Wu, M. Tyagi, T. Yildirim, W. Zhou and B. Chen, J. Am. Chem. Soc., 2014, 136, 6207; (c) B. Li, H.-M. Wen, W. Zhou and B. Chen, J. Phys. Chem. Lett., 2014, 5, 3468; (d) I. Senkovska and S. Kaskel, Chem. Commun., 2014, 50, 7089; (e) Z. R. Herm, E. D. Bloch and J. R. Long, Chem. Mater., 2014, 26, 323; $(f)$ Z. R. Herm, B. M. Wiers, J. A. Mason, J. M. van Baten, M. R. Hudson, P. Zajdel, C. M. Brown, N. Masciocchi, R. Krishna and J. R. Long, Science, 2013, 340, 960.

4 (a) Y. Bai, J. Qian, Q. Zhao, Y. Xu and S. Ye, J. Appl. Polym. Sci., 2006, 102, 2832; (b) S. Shimomura, S. Horike, R. Matsuda and S. Kitagawa, J. Am. Chem. Soc., 2007, 129, 10990; (c) J.-P. Zhang and X.-M. Chen, J. Am. Chem. Soc., 2008, 130, 6010; (d) H. Dong, X. Yang, G. Yue, W. Cao and J. Zhang, J. Chem. Eng. Data, 2011, 56, 2664.

5 (a) A. Takahashi and R. T. Yang, AIChE J., 2002, 48, 1457; (b) D. Barthomeuf and B.-H. Ha, J. Chem. Soc., Faraday Trans. 1, 1973, 69, 2147; (c) B.-H. Jeong, Y. Hasegawa, K.-I. Sotowa, K. Kusakabe and S. Morooka, J. Membr. Sci., 2003, 213, 115.

6 (a) G. Li, C. Zhu, X. Xi and Y. Cui, Chem. Commun., 2009, 2118; (b) J.-B. Lin, J.-P. Zhang, W.-X. Zhang, W. Xue, D.-X. Xue and X.-M. Chen, Inorg. Chem., 2009, 48, 6652; (c) R. Yang, L. Li, Y. Xiong, J.-R. Li, H.-C. Zhou and C.-Y. Su, Chem. - Asian J., 2010, 5, 2358; (d) S. Shimomura, R. Matsuda and S. Kitagawa, Chem. Mater., 2010, 22, 4129; (e) Y. Hijikata, S. Horike, M. Sugimoto, H. Sato, R. Matsuda and S. Kitagawa, Chem. - Eur. J., 2011, 17, 5138; $(f)$ G. Ren, S. Liu, F. Ma, F. Wei, Q. Tang, Y. Yang, D. Liang, S. Li and Y. Chen, J. Mater. Chem., 2011, 21, 15909; $(g)$ B. Joarder, S. Mukherjee, A. K. Chaudhari, A. V. Desai, B. Manna and S. K. Ghosh, Chem. - Eur. J., 2014, 20, 15303; (h) C.-X. Ren, L.-X. Cai, C. Chen, B. Tan, Y.-J. Zhang and J. Zhang, J. Mater. Chem. A, 2014, 2, 9015; (i) A. Karmakar, A. V. Desai, B. Manna, B. Joarder and S. K. Ghosh, Chem. - Eur. J., 2015, 21, 7071; $(j)$ J.-Y. Cheng, P. Wang, J.-P. Ma, Q.-K. Liu and Y.-B. Dong, Chem. Commun., 2014, 50, 13672.

7 (a) T.-L. Hu, H. Wang, B. Li, R. Krishna, H. Wu, W. Zhou, Y. Zhao, Y. Han, X. Wang, W. Zhu, Z. Yao, S. Xiang and B. Chen, Nat. Commun., 2015, 6, 7328; (b) Y. He, Z. Zhang, S. Xiang,
F. R. Fronczek, R. Krishna and B. Chen, Chem. Commun., 2012, 48, 6493; (c) S.-C. Xiang, Z. Zhang, C.-G. Zhao, K. Hong, X. Zhao, D.-R. Ding, M.-H. Xie, C.-D. Wu, M. C. Das, R. Gill, K. M. Thomas and B. Chen, Nat. Commun., 2011, 2, 204.

8 (a) D. Sun, S. Ma, Y. Ke, T. M. Petersen and H.-C. Zhou, Chem. Commun., 2005, 2663; (b) D. Sun, S. Ma, Y. Ke, D. J. Collins and H.-C. Zhou, J. Am. Chem. Soc., 2006, 128, 3896; (c) D. Sun, Y. Ke, D. J. Collins, G. A. Lorigan and H.-C. Zhou, Inorg. Chem., 2007, 46, 2725; (d) S. Ma, D. Sun, M. Ambrogio, J. A. Fillinger, S. Parkin and H.-C. Zhou, J. Am. Chem. Soc., 2007, 129, 1858; (e) W. Gao, F. Xing, D. Zhou, M. Shao and S. Zhu, Inorg. Chem. Commun., 2011, 14, 601.

9 H. Ren, T. Ben, E. Wang, X. Jing, M. Xue, B. Liu, Y. Cui, S. Qiu and G. Zhu, Chem. Commun., 2010, 46, 291.

10 (a) C. Graham, J. Pierrus and R. E. Raab, Mol. Phys., 1989, 67, 939; (b) A. D. Buckingham and R. L. Disch, Proc. R. Soc. A, 1963, 273, 275.

11 (a) A. R. Millward and O. M. Yaghi, J. Am. Chem. Soc., 2005, 127, 17998; (b) S. Couck, J. F. M. Denayer, G. V. Baron, T. Rémy, J. Gascon and F. Kapteijn, J. Am. Chem. Soc., 2009, 131, 6326; (c) A. Demessence, D. M. D'Alessandro, M. L. Foo and J. R. Long, J. Am. Chem. Soc., 2009, 131, 8784; (d) T. M. McDonald, D. M. D’Alessandro, R. Krishna and J. R. Long, Chem. Sci., 2011, 2, 2022; (e) P. Pachfule, Y. Chen, J. Jiang and R. Banerjee, J. Mater. Chem., 2011, 21, 17737.

12 (a) S. Horike, S. Shimomura and S. Kitagawa, Nat. Chem., 2009, 1, 695; (b) C. Serre, F. Millange, C. Thouvenot, M. Noguès, G. Marsolier, D. Louër and G. Férey, J. Am. Chem. Soc., 2002, 124, 13519; (c) D. Dubbeldam, R. Krishna and R. Q. Snurr, J. Phys. Chem. C, 2009, 113, 19317.

13 (a) C. Serre, F. Millange, C. Thouvenot, M. Noguès, G. Marsolier, D. Louër and G. Férey, J. Am. Chem. Soc., 2002, 124, 13519; (b) C. Serre, S. Bourrelly, A. Vimont, N. A. Ramsahye, G. Maurin, P. L. Llewellyn, M. Daturi, Y. Filinchuk, O. Leynaud, P. Barnes and G. Férey, Adv. Mater., 2007, 19, 2246; (c) Y. Yue, J. A. Rabone, H. Liu, S. M. Mahurin, M.-R. Li, H. Wang, Z. Lu, B. Chen, J. Wang, Y. Fang and S. Dai, J. Phys. Chem. C, 2015, 119, 9442.

14 R. Krishna, RSC Adv., 2015, 5, 52269. 